\title{
Artist Featured in Volume 1 IJMS: Rebecca Plummer-Rohloff, PhD
}

Aisha Charaibeh, ${ }^{1}$ Juliana Bonilla-Velez ${ }^{2}$

Rebecca Plummer-Rohloff is an Assistant Professor of Art Education at the Arts and Design Faculty at Salem State University, MA. Among her many professional areas of expertise, she is particularly interested in Expressive Art Therapy and Arts in Medicine. She as expressed that "my studio work is inspired by themes of impermanence, transformation, the imaginary, and biology"1 making her work very appealing to medical students.

She was an instructor and professor at several high schools and universities in the US, such as the Pennsylvania State University, the University of Illinois at Urbana-Champaign, Unity Junior and Senior High schools, among others. She has also taught English and Art in the JET program in Southern Japan after her graduation. She enjoys spending her summers in

For more information: http://rprgallery.com/gallery/ main php

www.salemstate.edu/ academics/schools/1039. php?id $=4383$

Guatemala advocating for Healthcare and Art Education. All of these experiences are reflected in her multiple publications. Furthermore, she has been certified in "Arts it Healing" from the Center on Arts, Healthcare, Research, and Education, (CAHRE), Arts in Medicine Program at Shands Hospital, University of Florida at Gainesville.

At the International Journal of Medical Students (IJMS) we are honoring an artist in each Volume who has been inspired by medicine and made significant contributions to the Arts. Three art pieces are chosen from the artist's repertoire for the cover of each issue. Due to her extensive trajectory and capturing art pieces, our historical first Volume exalted the work of Rebecca Plummer Rohloff, PhD. Thank you Dr. Plummer-Rohloff for your support throughout this year.

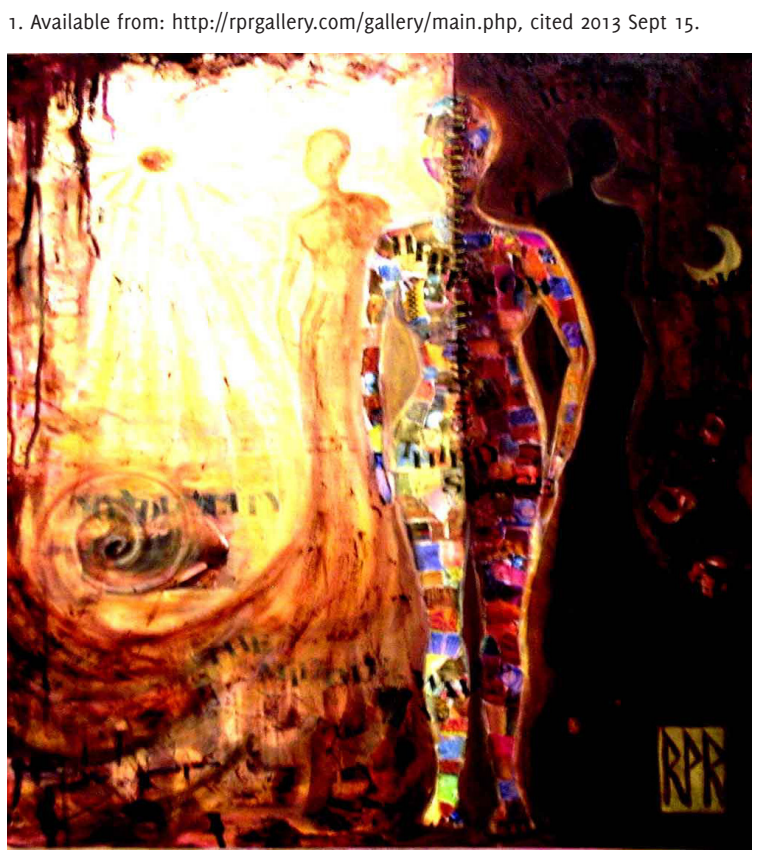

DSCN2308

Life Tapestries Collection

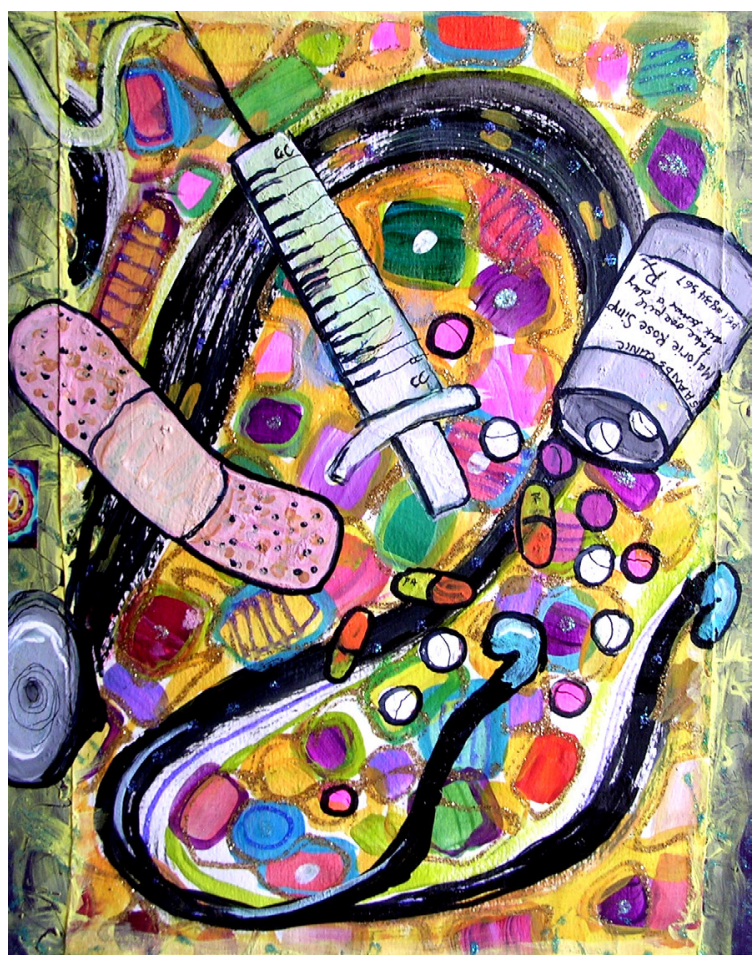

Healing: Where Art and Medicine Meet.

Arts in Medicine Imaginarium IV Collection.

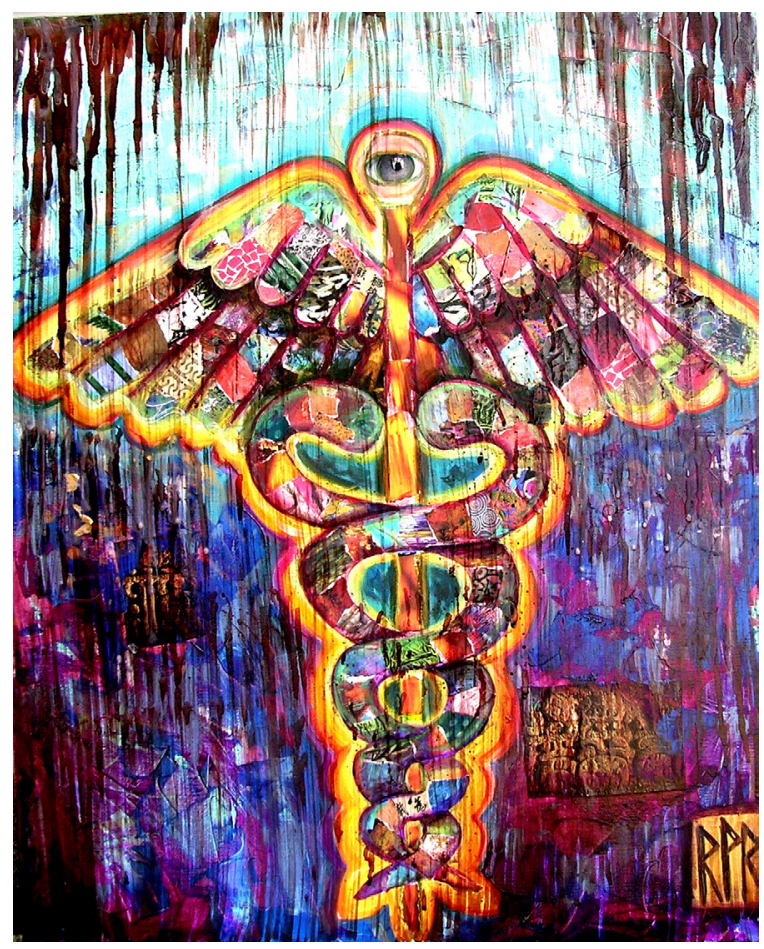

Cadeusus

${ }^{1}$ School of Medicine, Jordan University of Science and Technology, Ar Ramtha, Jordan.

${ }^{2}$ Department of Otolaryngology, Head and Neck Surgery, University of Arkansas for Medical Sciences, Little Rock, AR, USA 